\title{
Modern Aspects of Safety Assessment of Foodstuff
}

\author{
Tetiana Chorna ${ }^{1}$, Dmytro Yanushkevych ${ }^{1}$, Vita Afanasieva ${ }^{1}$ \\ ${ }^{1}$ Kharkiv Institute of Trade and Economics of Kyiv National University of Trade and Economics \\ 8 Otakara Yarosha street, Kharkiv, 61103, Ukraine
}

DOI: $10.22178 /$ pos.33-7

LCC Subject Category:

TP368-TP456

Received 13.03.2018

Accepted 14.04.2018

Published online 20.04.2018

Corresponding Author:

Tetiana Chorna

tatcher409@gmail.com

(c) 2018 The Authors. This

article is licensed under a

Creative Commons

Attribution 4.0 License

\begin{abstract}
Food safety is one of the decisive components of the economic security of each state and is determined by the ability of the country to control effectively the production and import of safe and high-quality food on the generally accepted principles of the world. This sphere of activity in human society has extremely important humanitarian, social, economic and political aspects.

The food raw materials and food products quality and safety control is currently the most relevant analytical task. It is more important than environmental pollution, according to some data, more than $70 \%$ of harmful pollutants in the human body gets through food, $20 \%$ of water and $10 \%$ of the air.

Technogenic pollution of the environment through soil, water and air gets directly into the food. However, food products are contaminated with natural harmful substances that appear in improper storage, in violation of technologies, food processing and processing charts.

The article is devoted to the main factors analysis influencing the safety of food products and the improvement of instrumental methods for the study of quality aromatic products (for example, coffee).
\end{abstract}

Keywords: food safety; analysis; regulation; chromatographic; instrumental methods.

\section{INTRODUCTION}

Food safety is one of the decisive components of the economic security of each state and is determined by the ability of the country to control effectively the production and import of safe and high-quality food on the generally accepted principles of the world. This sphere of activity in human society has extremely important humanitarian, social, economic and political aspects $[6,13]$.

United Nations General Assembly Resolution 217 was adopted on December 10,1948, to promote the Universal Declaration of Human Rights [10]. In accordance with Article 25 Resolution 217, everyone has the right to a standard of living adequate for the health and well-being of oneself and of one's family, including food, clothing, housing and medical care and necessary social services, and the right to security in the event of unemployment, sickness, disability, widowhood, old age or other lack of livelihood in circum- stances beyond his control. Meanwhile, the food should be of high quality, and the main indicator of its quality is safety.

The quality and safety control of food raw materials and food products is currently the most relevant analytical task. It is more important than environmental pollution, as according to some data, more than $70 \%$ of harmful pollutants in the human body gets through food, $20 \%$ of water and $10 \%$ of the air. Technogenic pollution of the environment through soil, water and air directly into the food. However, food products are contaminated with natural harmful substances that appear in improper storage, in violation of technologies, food processing and processing charts $[12,14]$.

In this connection, in recent years, human food security is most determined by the purity and quality of food, alcohol and soft drinks, as many harmful pollutants have carcinogenic, mutagenic and immunosuppressive effects. 
In addition to direct poisoning with low-quality foods and drinks, sometimes with fatal results, contaminated foods impair the immune system, the body's defences, and lead to changes in heredity and become the direct cause of the disease. In many cases, allergic, oncological, cardiovascular and other dangerous diseases are the result of a violation of biochemical reactions in the body, caused mainly by poor quality food.

The urgency of the research work consists in theoretical analysis of the current state of the question of the methodological approach to the use of instrumental methods in expert research on the quality and safety of goods; generalization of trends in the development and use of modern physic-chemical methods in the commodity evaluation of normalized indicators of food and non-food products that are implemented in the trading network of the Ukrainian market and the definition of counterfeit products.

\section{MATERIALS AND METHODS}

Access to sufficient amounts of safe and nutritious food is key to sustaining life and promoting good health. Foodborne diseases impede socioeconomic development by straining health care systems and harming national economies, tourism and trade.

Food supply chains now cross multiple national borders. Good collaboration between governments, producers and consumers helps ensure food safety. The main diseases associated with food are usually of infectious or toxic origin, and they are caused by bacteria, viruses, parasites or chemicals entering the body through contaminated food or water. WHO identifies key factors that concern the food safety $[11,14]$.

Chemical contamination can lead to acute poisoning or long-term diseases, such as cancer. Foodborne diseases may lead to long-lasting disability and death. Examples of unsafe food include uncooked foods of animal origin, fruits and vegetables contaminated with faeces, and raw shellfish containing marine biotoxins. First of all, they are: 1) Bacteria; 2) Viruses; 3) Parasites; 4) Prions; 5) Chemicals: naturally occurring toxins; persistent organic pollutants are compounds that accumulate in the environment and human body; heavy metals such as lead, cadmium and mercury cause neurological and kidney damage.

Figure 1 shows the main ways of the receipt of harmful substances to foods.

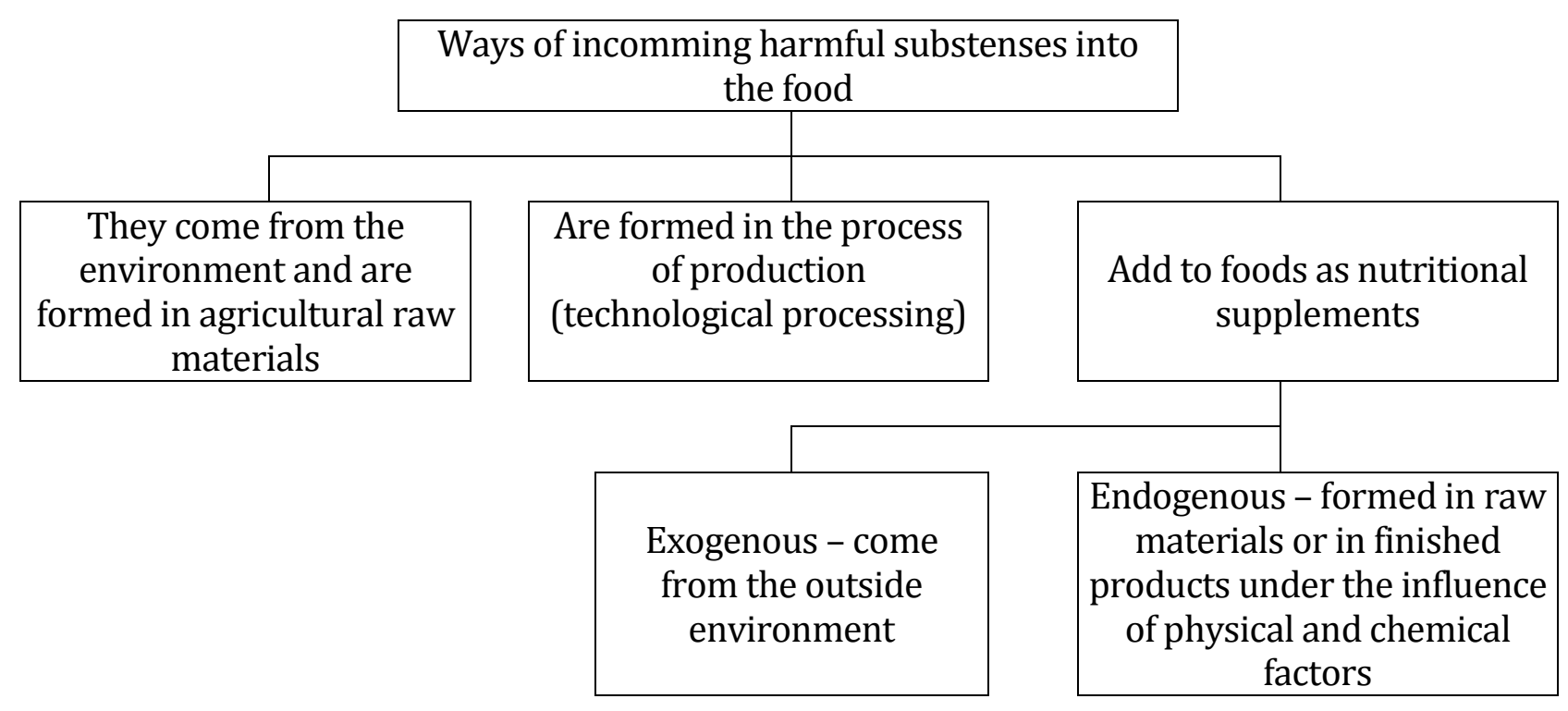

Figure 1 - The main ways of incomming of harmful substances into foods

Given Ukraine's aspirations to become a member of the EU, domestic producers of the food industry are urged to raise the level of control over the safety of products of their own production. Most of the existing methods for determining the quality of products used in domestic industries are intended for the use of food raw materials of a certain composition and origin. However, in the context of the globalization of the world market, there is a depersonalization of raw materials, fluctuations in its chemical composition and quality. Technological schemes for the produc- 
tion of the vast majority of types of food products are complex and combine several ways of modifying the raw material, therefore, this component - the determination of the quality and origin of primary raw materials - is most vulnerable in the process of monitoring and assessing compliance with consumer requirements. The objects of food expertise are complex multicomponent systems of biological and biochemical origin, in which various processes with the formation of new components occur during storage, transportation or technological processing, and the level of concentration of substances subject to control may be insignificant. In addition, in complex systems, some components can interfere with the definition of other substances, that is, mask their presence. All this complicates the analysis, so traditional physics-chemical methods do not reflect the complete picture of the quality of the product.

At present-day productions, chromatographic methods are widely used to control the quality of raw materials and products, which allow for research that cannot be carried out by other instrumental methods.

Chromatographic methods are based on the use of a wide range of physics-chemical processes: distribution, adsorption, ion exchange, diffusion, complex formation, etc.

The scope of chromatographic methods extends to the production of milk and dairy products, alcoholic and non-alcoholic beverages, vegetable oil confectionery products, and others. These methods are used to determine the products of water, alcohols, aldehydes, aromatic substances, higher fatty acids, herbicides or antibiotics, colorants. The methods of chromatography also determine the presence of non-characteristic impurities, traces of product damage. In general, chromatography can be considered as a universal method for the separation and analysis of complex mixtures of organic and inorganic substances contained in the food products and raw materials from which they are produced.

The methods of chromatographic analysis can determine the quantitative and qualitative composition of amino acids in proteins, simple and complex carbohydrates in confectionery and fruit mixtures, to establish the ratio of optical isomers of compounds, which allows us to draw conclusions regarding the natural or synthetic origin of the object. Since any method of processing raw materials leaves its unique label compounds, chromatographic methods can be used to verify the conformity of the conditions of technological processes to the production of normative docu- ments. Considering the possibilities and advantages of different types of chromatography, it is promising to develop, improve and extend the methods of analysis using chromatographic devices.

In Ukraine, there is also an acute problem of falsification of food products and food raw materials, due to the imperfection of legislation and the existence of enterprises of different forms of property supplying raw materials for food production or producing food products themselves. The expansion of the range of products is accompanied by the receipt on the consumer market of counterfeits or products of doubtful quality, so the methods of detecting falsifications of foodstuffs are of particular relevance. Thus, the issue of developing and implementing modern express control methods with the use of precision instrumentation for determining the chemical composition of raw materials and products, as well as the identification of individual substances, arises.

Many domestic and foreign scholars engaged in evaluating the quality and safety of food products and their falsifications. These include: Francis \& Annick Rouessac [8], D. C. Harris [9], F. David [1] etc. However, the problem of developing, improving and disseminating chromatographic analysis methods requires further development.

The Parliament of the European Union (EU) makes food safety legislation in the form of directives and regulations, many of which are mandatory for member states and which therefore must be incorporated into individual countries national legislation.

As a very large organisation that exists to remove barriers to trade between member states, and into which individual member states have only a proportional influence, the outcome is often seen as an excessively bureaucratic 'one size fits all' approach. However, in relation to food safety the tendency to err on the side of maximum protection for the consumer may be seen as a positive benefit. The EU parliament is informed on food safety matters by the European Food Safety Authority [3].

Individual member states may also have other legislation and controls in respect of food safety, provided that they do not prevent trade with other states, and can differ considerably in their internal structures and approaches to the regulatory control of food safety.

Indicative in the application of the provisions of Sanitary and Phytosanitary Measures (SPS) and Agreement on Technical Barriers to Trade (TBT) 
is the European Union, in which the distinction of state regulation of the food market from the technical one is as follows [2]:

1. The establishment of rules and regulations for foodstuffs is carried out, as a rule, on the basis of scientific evidence. For non-food products, rules and regulations can be defined taking into account the diverse objectives of state policy. Including, the goal may be to achieve an acceptable level of national security or a more "technical" task - electromagnetic compatibility.

2. As a rule, requirements for food products are defined in horizontal legislative acts, to non-food ones - in the format of technical regulations. At the same time, voluntary standards are used as a mechanism for fulfilling the mandatory requirements of these regulations.

3 . The most common types of legislative acts in the EU are directives and regulations. Moreover, if a directive defines only the main objectives to be achieved by a Member State, then the regulation is a document of direct action that defines all objectives and mechanisms for their implementation and does not require the adoption of addi- tional acts. Almost all documents regulating technical products have the format of the directive. And as for food, then the situation is exactly the opposite: there was a clear tendency to move from directives to regulations.

4. In the European Union for food products within the framework of state regulation, procedures for confirmation of conformity (including certification and declaration of conformity) are not applied.

5. The state control systems for technical and food products are also fully subdivided into the EU. Moreover, if the control of technical products is almost completely focused on the market, food control is carried out at all stages of their "life cycle" with particular attention to the stage of production.

In the European Union, not only the general normative and legal acts are effective, but also an extensive list of specific requirements and norms aimed at ensuring the safety of food products. The EU legislative framework for food safety is presented in Table 1.

Table 1 - Legislative base of the EU on food safety

\begin{tabular}{|c|c|c|c|c|}
\hline \multicolumn{5}{|c|}{$\begin{array}{c}\text { Regulation (EC) No 178/2002 of } 28.01 .2002 \\
\text { Establishes the fundamentals of food legislation: general principles, rules, definitions. Defines the basis for } \\
\text { harmonization of EU national legislation }\end{array}$} \\
\hline \multirow{2}{*}{\begin{tabular}{|c|} 
EU \\
regulations in \\
development
\end{tabular}} & \multicolumn{2}{|c|}{\begin{tabular}{|c|} 
Food hygiene \\
\end{tabular}} & \multicolumn{2}{|c|}{ Control system } \\
\hline & $\begin{array}{l}\text { Regulation } \\
\text { No 852/2004 }\end{array}$ & $\begin{array}{c}\text { Regulation } \\
\text { No } 853 / 2004\end{array}$ & $\begin{array}{l}\text { Regulation } \\
\text { No 882/2004 }\end{array}$ & $\begin{array}{c}\text { Regulation } \\
\text { No 854/2004 }\end{array}$ \\
\hline $\begin{array}{l}\text { The } \\
\text { objectives of } \\
\text { adoption }\end{array}$ & $\begin{array}{l}\text { Establishes general } \\
\text { rules for food hygiene, } \\
\text { duties of food business } \\
\text { operators }\end{array}$ & $\begin{array}{l}\text { Specific rules for the } \\
\text { hygiene of food } \\
\text { products of animal } \\
\text { origin }\end{array}$ & $\begin{array}{l}\text { Establishment of the } \\
\text { basis for the } \\
\text { establishment of } \\
\text { national control } \\
\text { systems }\end{array}$ & $\begin{array}{l}\text { Specific rules for } \\
\text { the organization of } \\
\text { official control } \\
\text { over products of } \\
\text { animal origin }\end{array}$ \\
\hline Scope & $\begin{array}{l}\text { All stages of } \\
\text { production, processing } \\
\text { and sale, including the } \\
\text { implementation of } \\
\text { export-import } \\
\text { operations }\end{array}$ & $\begin{array}{l}\text { They are applied to raw } \\
\text { and processed products } \\
\text { of animal origin. The } \\
\text { action does not apply to } \\
\text { retailers }\end{array}$ & $\begin{array}{l}\text { All stages of } \\
\text { production, } \\
\text { processing and sale }\end{array}$ & $\begin{array}{l}\text { Distributed only in } \\
\text { relation to the } \\
\text { activities of } \\
\text { persons to whom } \\
\text { the EU Regulation } \\
\text { No. } 853 / 2004 \\
\text { applies }\end{array}$ \\
\hline $\begin{array}{l}\text { Basic } \\
\text { provisions }\end{array}$ & $\begin{array}{l}\text { Responsibility of food } \\
\text { business operators; } \\
\text { transparency of the } \\
\text { food chain; the } \\
\text { principle of flexibility; } \\
\text { introduction of the } \\
\text { HACCP system }\end{array}$ & $\begin{array}{l}\text { Special requirements } \\
\text { for enterprises for } \\
\text { placing products of } \\
\text { animal origin; } \\
\text { compulsory sanitary } \\
\text { and identification } \\
\text { marks; special } \\
\text { guarantees for certain } \\
\text { types of meat products }\end{array}$ & $\begin{array}{l}\text { Obligation of official } \\
\text { control; regularity } \\
\text { and proportionality } \\
\text { of inspections; } \\
\text { verification as a } \\
\text { warning, not a } \\
\text { punishment. }\end{array}$ & $\begin{array}{l}\text { Assistance to } \\
\text { regulatory } \\
\text { authorities; risk } \\
\text { analysis; special } \\
\text { periods of control, } \\
\text { depending on the } \\
\text { type of product. }\end{array}$ \\
\hline
\end{tabular}


For consumers, food safety is the most important characteristic of food quality. Consumers in all countries of the world expect that food will be safe. According to the WHO standards, a high level of protection of human life and health must be ensured. In most countries of the world, the provision on food safety, protection of human life and health, as well as protection against unfair market practices are introduced in the constitution and the basic legislative acts of all countries of the world.

The basic principles of regulation are contained in the Foodstuffs Act, European Parliament and Council Regulation (EC) No 178/2002 laying down the general principles and requirements of food law, establishing the European Food Safety Authority and laying down procedures in matters of food safety. All regulations operate in the member countries directly, that is, without discussion in the legislation of each individual country [3].

Regulation establishes the common basis for food law in Member States and includes common definitions, general provisions and specific requirements. This Regulation also established the European Food Safety Authority (EFSA) and laid down the procedures in matters of food safety. The objective of the Regulation is to ensure a high level of protection for consumers whilst also taking into account the protection of animal health and welfare, plant health and the environment.

The Regulation sets out the general requirements of food law which include food safety requirements, responsibilities of both food and feed business operators and Member States. The Regulation establishes the principle that the primary responsibility for ensuring compliance with food law, rests with the food business operator.

Food business is defined in the Regulation as meaning any undertaking, whether for profit or not and whether public or private, carrying out any of the activities related to any stage of production, processing and distribution of food. Food business operator means the natural or legal persons responsible for ensuring that the requirements of food law are met within the food business under their control. The European Commission has published a poster on the Key obligations of the food business operators (Table 2).
Table 2 - Key obligations of the food business operators $[4,5]$

\begin{tabular}{|l|l|}
\hline Key obligations & \multicolumn{1}{|c|}{$\begin{array}{c}\text { Requirements for food } \\
\text { operators }\end{array}$} \\
\hline Safety & $\begin{array}{l}\text { Operators shall not place on the } \\
\text { market unsafe food or feed }\end{array}$ \\
\hline Responsibility & $\begin{array}{l}\text { Operators are responsible for } \\
\text { the safety of the food and feed } \\
\text { which they produce, transport, } \\
\text { store or sell }\end{array}$ \\
\hline Traceability & $\begin{array}{l}\text { Operators shall be able to } \\
\text { rapidly identify any supplier or } \\
\text { consignee }\end{array}$ \\
\hline Transparency & $\begin{array}{l}\text { Operators shall immediately } \\
\text { inform the competent } \\
\text { authorities if they have a reason } \\
\text { to believe that their food or feed } \\
\text { is not safe }\end{array}$ \\
\hline Emergency & $\begin{array}{l}\text { Operators shall immediately } \\
\text { withdraw food or feed from the } \\
\text { market if they have a reason to } \\
\text { believe that it is not safe }\end{array}$ \\
\hline Prevention & $\begin{array}{l}\text { Operators shall identify and } \\
\text { regularly review the critical } \\
\text { points in their processes and } \\
\text { ensure that controls are applied } \\
\text { at these points }\end{array}$ \\
\hline $\begin{array}{l}\text { Operators shall co-operate with } \\
\text { the competent authorities in } \\
\text { actions taken to reduce risks }\end{array}$ \\
\hline
\end{tabular}

Regulation No 178/2002 defines food as any substance or product, whether processed, partially processed or unprocessed, intended to be, or reasonably expected to be ingested by humans.

"Food" includes drink, chewing gum and any substance, including water, intentionally incorporated into the food during its manufacture, preparation or treatment. It includes water after the point of compliance as defined in Article 6 of Directive 98/83/EC and without prejudice to the requirements of Directive 2009/54/EC and 98/83/EC.

In accordance with the EU Regulations, modern methods should be used to study food safety indicators. One of the most promising is chromatographic methods.

Chromatographic methods are widely used in various industrial branches and scientific researchers for the analysis of mixtures of gaseous, liquid and solid substances, for preparative selec- 
tion of compounds and studying of physicchemical properties of gases and solutions. The quality control of raw materials, intermediate products and final products is carried out mainly using chromatographic methods of analysis (up to $50 \%$ ) at factories of the national economy.

Chromatography is a physic-chemical method for separating substances, based on the distribution of components between two phases (stationary and mobile). The stationary phase is usually a solid (sorbent) or a liquid film applied to a solid. The mobile phase is a liquid or gas flowing through a stationary phase. The components of the analyzed mixture together with the moving phase are moved along the stationary phase, which is usually placed in the column (glass or metal tube). If the molecules of different components of the mixture have a different adsorption property or solubility, then the time of their stay in the stationary phase, and, consequently, the average speed of movement on the column are different. Some components remain in the upper layer of the sorbent; others, with a lower adsorption property, are found at the bottom of the column; some leave the column along with the moving phase. This is achieved by separating the components. Chromatography is a dynamic method associated with multiple repetitions of sorption and desorption processes, as separation occurs in the flow of a mobile phase. This ensures the efficiency of the chromatographic method compared to the methods of sorption in static conditions. It is possible with the help of chromatography: the division of complex mixtures of organic and inorganic substances into individual components, purification of substances from impurities, concentration of substances with a strongly diluted solution, qualitative and quantitative substance analysis [1].

The basis for the classification of chromatographic analysis methods has following feautures: the aggregate state of the phases; the mechanism of interaction sorbent - sorbate; methods of chromatographic analysis; equipment of the process of chromatography; the purpose of chromatography.

According to the aggregate state of the phase, the chromatography is divided into gas and liquid. Gas chromatography includes gaseous gas and gas-solid phase, liquid-liquid and liquid-solid phase. The method of gas chromatography is most widely used as the theory and equipment for it was most fully developed.
Gas chromatography is a hybrid method that allows both separation and determination of components of a mixture to be carried out. As a mobile phase (carrier gas), gases, their mixtures or compounds that are in a gaseous or vaporous state are used. As a stationary phase, solid sorbents (gas adsorption chromatography) or a liquid applied to a surface of an inert carrier (gasliquid chromatography) is applied.

Advantages of gas chromatography: the possibility of identification and quantitative determination of individual components of complex mixtures; the possibility of analyzing a wide range of objects - from light gases to high molecular organic compounds; the possibility of the allocation of pure substances in the preparatory and industrial scale.

Gas adsorption chromatography. In the gas adsorption chromatography (GAC), the separation of the analyzed components is based on their different alliance for solid adsorbents. Chromatography repeats the process of adsorption of the separated components by grains of the adsorbent and their desorption into the mobile gaseous phase. The selectivity of the adsorbent is determined by the manner and strength of the interactions of the divided substances with the surface of the adsorbent. In this connection adsorbents with reduced adsorption activity are used for the division of polar compounds, and adsorbents with high adsorption capacity are used for the division of nonpolar substances.

Types of adsorbents: non-specific nonpolar adsorbents, there are no functional groups and ions on their surface; specific adsorbents that have positive charges on the surface; specific adsorbents that have a bonding surface or a group of atoms with high electron density.

GAC advantage is high resolution in the analysis of mixtures of gases and vapors of low boiling materials, high thermal stability and nonvolatility of adsorbents can analyze highconnection without compromising sensitivity detectors. A high rate mass exchange processes compared to gas-liquid chromatography, which reduces the performing analyzes is typically for GAC.

The basis of the gas-liquid chromatography (GLC) is the phenomenon of selective absorption (dissolution) of the components of the mixture with a stationary liquid phase - an absorbent. The stationary liquid phase in the form of a film 
is applied to the inner walls of the capillary column or to the grain of the solid carrier, which is filled by the packed column. For the separation of components of the mixture, the forces of interaction of gas molecules or vapor of a chromatographing substance with absorber molecules are crucial. These forces depend on the structure and properties of molecules of both the stationary liquid phase and the analyzed substances.

The GLC method has broader analytical capabilities compared to GACs, as the selectivity of dissolution of gases in a liquid film is much greater than the difference in their adsorption properties. Significant advantage of GLC against GAC is that the absorption isotherm is linear over a wider concentration range than the isotherm of adsorption.

Thin-layer chromatography is a chromatographic method based on the use of a thin layer of adsorbent as a stationary phase. It is based on the fact that substances that are separated in different ways between the absorbing layer and flows through it by the eluent, so that the distance to which these substances are displaced in a layer for one and the same time, is different. Thin-layer chromatography provides great opportunities for analysis and separation of substances, as both the sorbent and the eluent can vary widely. In this case, commercially available series of plates with different sorbents, which makes possible the rapid and routine use of the method. A kind of thin-layer chromatography is a more reliable and reproducible high-performance thin-layer chromatography, in which the special plates and complex equipment are used. TLC is used in the following directions: demonstration of chromatographic basis, rapid preliminary experiments to optimize preparative chromatographic separations; research tools in academic and applied industrial research work are used to study a large number of samples; identification of medical and food plant components by validated methods with increased requirements for accuracy, reproducibility and sensitivity.

Depending on the purpose of the chromatographic process, analytical chromatography (qualitative and quantitative analysis); preparative chromatography (for obtaining substances in pure form, for concentration and isolation of micro-mixes); industrial chromatography for automatic process control are distinguished. Chromatography is often used for research purposes in the study of solutions, catalytic processes, chemical processes, etc.
Classification by methods of analysis divides chromatography into three types: frontal; elution; displacement;

The frontal method is the easiest to execute. Through a chromatographic column with a sorbent, a continuous flow of a solution or gas mixture of the substances is passed through a continuous stream. Accordingly, these components are located in the column. However, they are not completely separated. Only the first, most weakly sorbable component, which moves along the sorbent layer in front of others, can be isolated in its pure form. The zone of the first component with direct contact is located behind the zone containing the first and second components. The third zone contains a mixture of the first, second and third components. At some point in time, the sorbent is saturated, and there is a "bypassing", that is, the column begins to come out components in accordance with their sorption. Typical examples of frontal analysis: water purification and softening by ion-exchange materials; purification of drugs and food products using saturated ion exchangers.

The elution method of analysis has been widely used in both liquid and gas chromatography. This is explained by the fact that, with the right choice of separation conditions, the components of the mixture come out of the column in its pure form, and they can be isolated for research by other methods of analysis. In addition, the qualitative and quantitative composition of the analyzed mixture can be determined by a simple measurement of the volume of containment and the area of the peaks of the corresponding components on the resulting chromatogram.

The method of atomic absorption spectrometry is currently one of the most advanced methods of elemental analysis. It combines the high sensitivity of the identification, sufficient selectivity, the ability to identify a large group of elements from one prepared sample, as well as a relatively low cost of equipment and analyzes. The method is widely used in various fields of production, in scientific and environmental research for the analysis of food systems.

Together with various chemical methods of preparation of samples for analysis, it enables the quantification of a large number of macro- and trace elements in the listed objects. Using a combination of various variants of the technique of atomic absorption spectrometry makes this 
method the most suitable for determining the content of a large number of elements (about 70) in a wide range of concentrations.

Atomic absorption analysis refers to spectral methods. It is based on the transfering of the sample into atomic vapor and the identification of the degree of absorption by the atoms of the element, the radiation of a standard light source.

Atomic absorption analysis is a method of quantitative elemental analysis in atomic absorption spectra (absorption). The atomic vapor samples obtained with the aid of an atomizer pass the radiation in the range of $190-850 \mathrm{~nm}$. As a result of the absorption of light quanta, atoms move to tense energy states. These transitions in atomic spectra correspond to the resonance lines characteristic of this element.

At a certain wavelength, corresponding to the optical transition of the atom from the main state to the tense level, the absorption of radiation leads to a decrease of the basic level. The size of the analytical signal is related to the concentration of atoms in the non-tense state and, consequently, to the concentration of the element in the analyzed sample. By measuring the proportion of absorbed electromagnetic radiation, it is possible to determine quantitatively the content of the compounds of the detectable element (analyte).

A quantitative atomic absorption method is based on the main law of light absorption, which binds the adsorption (optical density) of atomic vapor with the concentration of a detectable element.

The basic law of atomic absorption analysis is the Bouguer-Lambert-Beer (1) law and it has the following form:

$$
A=-\lg T=\lg \left(\frac{I_{0}}{I}\right)=\varepsilon C L,
$$

where $T$ - transmittance;

$A$ - optical density;

$I_{0}$ - intensity of the initial radiation flux;

$I$ - intensity of the final radiation flux;

$L$ - the thickness of the absorbent layer;

$C$ - concentration of the detectable element;

$\varepsilon$ - molar absorption coefficient [7].

Equation (1) is used to calibrate atomic absorption devices. However, this fundamental theo- retical dependence may be broken. The main reasons for the deviation of the dependence of optical density and concentration on the linearity are equipment limitations and side physical and chemical processes. Determination of some elements using atomic absorption spectrometry is given in Table 3.

Table 3 - Determination of some elements by atomic absorption spectrometry

\begin{tabular}{|l|l|}
\hline \multicolumn{1}{|c|}{ The object of analysis } & \multicolumn{1}{|c|}{ Elements } \\
\hline $\begin{array}{l}\text { Surface water and } \\
\text { sewage }\end{array}$ & $\mathrm{Cu}$ \\
\hline $\begin{array}{l}\text { Natural and purified } \\
\text { sewage }\end{array}$ & $\begin{array}{l}\mathrm{Pb}, \mathrm{Zn}, \mathrm{Ag}, \mathrm{Cu}, \mathrm{Cr}, \mathrm{Co}, \\
\mathrm{Ni}, \mathrm{Fe}, \mathrm{Mn}, \mathrm{Cr}\end{array}$ \\
\hline Seawater & $\begin{array}{l}\mathrm{Cd}, \mathrm{Cu}, \mathrm{Pb}, \mathrm{Co}, \mathrm{Ni}, \mathrm{Fe}, \\
\mathrm{Mn}, \mathrm{Cr}\end{array}$ \\
\hline $\begin{array}{l}\text { Atmospheric air, air } \\
\text { work }\end{array}$ & $\mathrm{Pb}$ \\
\hline $\begin{array}{l}\text { Soils, dumps, bottom } \\
\text { sediments }\end{array}$ & $\mathrm{Cd}, \mathrm{Cu}, \mathrm{Ni}, \mathrm{Hg}, \mathrm{Pd}, \mathrm{Zn}$ \\
\hline $\begin{array}{l}\text { Raw materials and food } \\
\text { products }\end{array}$ & $\mathrm{Cd}, \mathrm{Cu}, \mathrm{Zn}, \mathrm{Fe}, \mathrm{Pb}$ \\
\hline Zinc alloys & $\mathrm{Al}, \mathrm{Cu}, \mathrm{Mg}, \mathrm{Pb}, \mathrm{Cd}, \mathrm{Fe}$ \\
\hline
\end{tabular}

Principle scheme of a flaming atomic absorption spectrometer: source of radiation; flame; monochromator; photomultiplier; registering device.

The advantages of atomic absorption analysis can be: simplicity, high selectivity, small influence of the sample on the results of the analysis.

Limitation of the method is the impossibility of simultaneous determination of several elements while using line radiation sources and, as a rule, the need to transfer of samples into a solution.

In modern laboratory physicochemical analysis, spectral methods are widely used. These methods are increasingly used in technological analysis of food systems, household chemistry, chemical and pharmaceutical preparations, etc. Spectrophotometric method is based on the quantitative determination of the value characterizing the absorption of this substance by monochromatic radiation of different wavelengths. These values can be used both for quantitative characterization of a substance and for quantitative determination in a solution or in a mixture with other substances. Among the optical methods, the most accessible, and therefore the most common are visible and ultraviolet (UV) spectrophotometry, 
which allows quickly and accurately carry out quantitative analysis of substances.

Spectrophotometry in the visible region and UV regions allows us to evaluate the degree of purity of a substance, to identify various compounds in the spectrum, to determine the constants of dissociation of acids and bases, to investigate the processes of complexation.

Infrared $(I R)$ spectra give a characteristic of substances. The presence in $I R$ spectra of certain absorption bands allows us to decipher the structure of the substance.

The method of $U V$ spectrophotometry is used to determine the identity, purity and quantitative content of medicinal products.

The study of the spectra of absorption of chemicals with different structures made it possible to establish that the main factors that determine the absorption of light are the presence of so-called chromophore, unsaturation (double or triple bonds), the presence of carbonyl, carboxylic, amide, azo-, nitroso-, nitro- and other functional groups. Each functional group is characterized by absorption in a certain region of the spectrum. But there are a number of factors (the presence of several chromophore groups, the influence of the solvent, etc.) leads to the displacement of absorption bands towards the larger wavelengths (bathochromic shift) or toward short wavelengths (hypsochromic shift). In addition to the shift, the effect of increasing (hyperchromic) or decreasing (hypsochromic) absorption intensity may be observed.

The spectrophotometric method of analysis is based on the general principle - the proportional dependence between the light absorption of a substance, its concentration and the thickness of the absorbing layer. The Beer-Lambert law is used to determine the concentration of solutions by the spectrophotometric method:

$$
C=\frac{1}{x \cdot b} \times D
$$

where $C$ - the concentration of the test substance in percentages;

$b$ - the thickness of the layer of substance in centimeters;

$x$ - the rate of absorption of a solution, the concentration of which is equal to one;

$D$ - optical density.
The development of methodological approach to the improvement and use of instrumental research methods. In the last few years, the number of coffee importers in the Ukrainian retail chain has increased significantly, among which there are those that supply coffee illegally. Therefore, there is a question of examination of the quality and safety of the coffee segment production.

Today are known the following most common methods of falsification of natural ground coffee: assortment falsification that is coffee substitution by various coffee substitutes, qualitative falsification, quantitative falsification, informational falsification. Assortment falsification is quite well represented on the coffee market. It involves substituting one sort of coffee for another, or replacing natural coffee with various coffee substitutes.

The substitute for natural coffee with assortment falsification are all kinds of dried, roasted and ground components from the flora: different kinds of roots - chicory, beets, carrots, dandelion; sugar-rich products - burnt sugar, wine berries; rich starch substance - acorns of various types of oak, chestnuts, rye, barley, oats, wheat, barley malt; seeds of legumes - ordinary peas, coffee peas, Chinese beans; ordinary beans; fatty substances - American nut, walnut, groundnut.

Since these tamperings do not contain the two most important constituents of coffee - caffeine and cafiolum, they have no exerting effect on the central nervous system. The widespread distribution of chicory and coffee substitutes of wine grapes has been due to their higher extractivity than natural coffee, and therefore they are often used to falsify instant coffee.

Sometimes the "Extra" Class coffee is given out for coffee beans of various sizes and color, indicating the existing mixing of waste coffee production, which is unacceptable, because it must be necessarily implemented coffee of one batch, which consists of one class and one degree of roasting.

Methods of detecting substitution of coffee of different coffee substitutes can be organoleptic and physics-chemical. Organoleptic is: an estimation of the taste, smell and color of the extract. At the same time the attention is paid to the presence of rough taste and weak coffee smell, too dark or weak color infusion, its opacity, turbidity. The natural coffee is characterized by a combination of three taste sensations: sour, bitter and tart. The coffee substitutes have only one taste - bit- 
terness. When dissolving ground coffee in cold water, coffee particles containing carbon dioxide can be above the water for a long time, and particles of coffee substitutes quickly sink to the bottom.

Qualitative falsification of coffee is achieved in the following way: the usage of supplements not provided for in the formulation; the usage of another substances and components, the preparation of artificial grains.

In order to increase the weight of coffee beans during roasting, they are sprayed with vaseline, sugar syrup or other low-value substances. To mask the spoiled ones, which have lost their natural color and consistency of grains, they are shaken with lead balls or often painted with dyes that are harmful to health. Most commonly found tampering of fried ground coffee, which is mixed with all kinds of coffee substitutes in fried and crushed form.

Quantitative falsification of coffee is a consumer fraud at the expense of significant variations in product options (weight) exceeding the maximum permissible deviations. For example, the net weight of a pack is understated, or the tin cans of greater mass are used, etc.

Informational falsification is a consumer fraud with inaccurate or distorted product information. This kind of falsification is carried out by distorting information in commodity-accompanying documents; marking; not complete information on the packaging; advertising. When falsifying coffee information, the following data are often misrepresented or inaccurately indicated: the name of the product, the country of origin of the product, the firm-producer of the product, the quantity of the product. Informational falsification includes tampering of a certificate of quality, customs documents, barcode.

\section{RESULTS AND DISCUSSION}

In order to detect falsification characteristics in samples that were selected for research, for determining caffeine and chlorogenic acid in natural ground coffee using a method of highly effective liquid chromatography was developed a concept.

The determination was carried out on a liquid chromatograph "Agilent 1100" with a diodematrix detector equipped with a degasifier, a four-channel pump and an autosampler under the following conditions:
- isocratic elution regime, mobile phase buffer acetonitrile in the ratio of 90:10;

- $150 \mathrm{~mm}$ column with a stationary phase Prontosil 120-5C18AQ; UV detection was carried out in the wavelength range of $200-310 \mathrm{~nm}$. Sample volume $-5 \mu \mathrm{l}$ (autosampler). Speed of the mobile phase $-1 \mathrm{ml} / \mathrm{min}$.

The preparation of a buffer solution: $2.4 \mathrm{~g}$ of sodium dihydrogen phosphate was dissolved in 1 litre of water and adjusted to $\mathrm{pH} 2.3$ with concentrated o-phosphoric acid. Then 1 cansulfonate sodium was added to the solution and stirred until it was completely dissolved. The solution was filtered through a membrane filter with pore diameter of $0.45 \mu \mathrm{m}$. The preparation of a standard sample solution: $250 \mathrm{mg}$ of standard sample of caffeine was placed in a $100 \mathrm{ml}$ flask and dissolved in water for chromatography, brought to the label with the same solvent. Then, $5 \mathrm{ml}$ of the resulting solution was placed in a $50 \mathrm{ml}$ flask, added with water for chromatography to the label, and thoroughly mixed.

Preparation of samples for analysis: on analytical scales were taken approximately 0,15 g (precise weight loss). The sample was placed in a roundbottomed flask, which was added $10 \mathrm{ml}$ of water. The solution was boiled under the reflux condenser for 60 minutes. The solution was then filtered through a membrane filter with a pore diameter of $0.45 \mu \mathrm{m}$. The filtrate was chromatographed under the above conditions.

Concentration of caffeine in samples $(\mathrm{X})$ was calculated according to the following equation (3):

$$
X=\frac{S_{c a f} \times m_{s t d}}{S_{s t d} \times m_{c a f}} \times 100
$$

where $S_{c a f}$ - peak area of caffeine in experimental samples;

$m_{s t d}$ - is the weight of a standard sample;

$S_{s t d}$ - peak area of the standard sample;

$m_{\text {caf }}-$ is the weight of the test sample.

In the methods described in the literature, diethylamine is used as an ion-dual reagent, but its use has not achieved the necessary selectivity. Therefore, as a ion-dual reagent, we were offered to use sodium decansulfonate. It justifies itself in usage, since the peaks of caffeine and chlorogenic acid are completely separated, indicating the necessary selectivity. 
Table 4 - Results of determination on the content of caffeine and chlorogenic acid in the studied samples

\begin{tabular}{|l|r|r|r|r|r|r|r|r|}
\hline No & \multicolumn{1}{c|}{ mcaf } & \multicolumn{1}{c|}{ Scaf } & \multicolumn{1}{c|}{ SChlor.acid } & \multicolumn{2}{|c|}{ Scaf /SChlor.acid } & X (mg) & Sstd & bulk part, w \\
\hline 1 & 0,1762 & 11701,2 & 1112,87 & 10,51444 & - & 11,23435 & 2603,89 & 63,75906 \\
\hline 2 & 0,2654 & 17313,4 & 3401 & 5,090679 & - & 16,62263 & & 62,63237 \\
\hline 3 & 0,1275 & 8759,57 & 1583,2 & 5,532826 & - & 8,410081 & & 65,96142 \\
\hline 4 & 0,1326 & 9189,49 & 1894,92 & 4,84954 & - & 8,822848 & & 66,53731 \\
\hline 5 & 0,1412 & 10337,3 & 1341,56 & 7,705432 & - & 9,924862 & & 70,28939 \\
\hline 6 & 0,1654 & 12678,6 & 1283,38 & 9,879069 & - & 12,17275 & & 73,59582 \\
\hline 7 & 0,1387 & 12672,1 & 2262,05 & 5,602042 & - & 12,16651 & & 87,71816 \\
\hline 8 & 0,2212 & 15689,1 & 1168,52 & 13,42647 & X & 15,06314 & & 68,09736 \\
\hline 9 & 0,248 & 10286,5 & 2284,02 & 4,503682 & - & 9,876089 & & 39,82294 \\
\hline 10 & 0,1505 & 8529,29 & 495,35 & 17,21871 & X & 8,188988 & & 54,41188 \\
\hline
\end{tabular}

An improved chromatographic system is proposed to improve the separation of chromatographic peaks and provide a reliable identification of chlorogenic acid. As a working wavelength, it was decided to use a wavelength of 230 $\mathrm{nm}$, because it was the maximal response of the detector to caffeine. The extraction of caffeine and chlorogenic acid was carried out during 1, 2, 3 hours, and it was found that for 1 hour, caffeine and chlorogenic acid completely transfer into an aqueous solution.

Sample No 9 is a real example of counterfeit coffee, because it has a low content of caffeine, although the ratio of caffeine to chlorogenic acid is 4.5. Sample No 8 and No 10 have signs of falsification, since the ratio of caffeine to chlorogenic acid is strongly overestimated in comparison with other samples and the content of caffeine in these samples is very small, as compared to other test samples.

\section{CONCLUSION}

Thus, the desire of Ukraine to become a member of the EU requires domestic producers of food products to increase control over their production. Most of the existing methods for determining the quality of products used in domestic industries are intended for the use of food raw materials of a certain composition and origin. However, in the context of the globalization of the world market, there is a fluctuation in its chemical composition and quality. Technological schemes for the production of the vast majority of types of food products are complex and combine several ways of modifying the raw material, therefore, this component - the determination of the quality and origin of primary raw materials - is most vulnerable in the process of monitoring and assessing compliance with consumer requirements.

Thereby, as a result of the research carried out, the methodology and advanced methods of researching the quality and safety of food products have been theoretically substantiated, developed and implemented, namely:

1. An analytical assessment of the food safety system is provided in accordance with the requirements of the EU.

2. Theoretical analysis of the current state of the methodological approach to the use of instrumental methods in the expert research on the quality and safety of food products is conducted.

3. The tendencies of development and use of modern physics-chemical methods at the commodity evaluation of normalized indicators of food safety are generalized.

4. Developed methodology and advanced method of determination of caffeine and chlorogenic acid in natural molten coffee.

The objects of food expertise are complex multicomponent systems of biological and biochemical origin, in which various processes with the formation of new components occur during storage, transportation or technological processing, and the level of concentration of substances subject to control may be insignificant. In addition, in complex systems, some components can interfere with the detection of other substances, that is, mask their presence. All this complicates the analysis, so traditional physics-chemical methods do not reflect the complete picture of the quality of the product. Therefore, food expertise requires further development and improvement. 


\section{REFERENCES}

1. David, F., Sandra, P., \& STAFFORD, S. (1994). Application of retention gaps for optimized capillary GC. Hewlett Packard Application Note, 228-245, 1-11.

2. European Commission. (2016). General principles of food law. Retrieved April 1, 2018, from https://www.fsai.ie/legislation/food_legislation/general_principles_of_food_law.html

3. General Principles of Food Law (European Parliament and of the Council), 28 January 2002, No 178/2002. Retrieved April 1, 2018, from

https://www.fsai.ie/uploadedFiles/Legislation/Food_Legisation_Links/General_Principles_of_F ood_Law/Consol_Reg178_2002.pdf

4. Health \& Consumer Protection Directorate-General. (2007, June). Food traceability. Retrieved from https://ec.europa.eu/food/sites/food/files/safety/docs/gfl_req_factsheet_traceability_2007_en. pdf

5. Health \& Consumer Protection Directorate-General. (n. d.). The key obligations of food and feed business operators. Retrieved April 1, 2018, from

https://ec.europa.eu/food/sites/food/files/safety/docs/gfl_req_business_operators_obligations _en.pdf

6. Jonsson, U. (2003). Human Rights Approach to Development Programming. New York: UNICEF.

7. Opeida, Y., \& Shvaika, O. (2008). Hlosarii terminiv z khimii [Glossary of terms on chemistry]. Donetsk: Donetskyi Natsionalnyi universytet im. V. Stusa (in Ukrainian) [Опейда, Й., \& Швайка, О. (2008). Глосарій термінів з хімії. Донецьк: Донецький Національний університет ім. В. Стуса].

8. Rouessac, F., \& Rouessac, A. (2007). Chemical Analysis: Modern Instrumentation Methods and Techniques. Hoboken, USA: John Wiley \& Sons.

9. Steehler, J. K. (2005). Exploring Chemical Analysis, 3rd Edition (Daniel C. Harris). Journal of Chemical Education, 82(5), 685. doi: 10.1021/ed082p685.1

10. Universal Declaration of Human Rights (United National), 10 December 1948, No A/RES/3/217 A. Retrieved April 1, 2018, from http://www.un-documents.net/a3r217a.htm

11. World Health Organization. (2007). Five keys to safer food. Geneva: World Health Organization.

12. World Health Organization. (2017). Food safety. Fact sheet. Retrieved April 1, 2018, from http://www.who.int/mediacentre/factsheets/fs399/en

13. World Health Organization. (2018). Food safety. Retrieved April 1, 2018, from http://www.who.int/foodsafety/areas_work/en

14. World Health Organization. (n. d.). Foodborne diseases. Retrieved April 1, 2018, from http://www.who.int/foodsafety/areas_work/foodborne-diseases 